\title{
Photochemical Initiation of Cationic Polymerization and Its Kinetics
}

\author{
G. SMets, A. Aerts, and J. Van ERum \\ Laboratory of Macromolecular Chemistry, Katholieke Universiteit Leuven, \\ B-3030 Heverlee, Belgium.
}

(Received April 15, 1980)

\begin{abstract}
The photochemical dissociation of different diazonium salts has been examined from the point of view of its quantum yield, its photosensitization and its ability to initiate the cationic polymerization of $N$-vinylcarbazole and the cross-linking of glycidyl methacrylate copolymers. These results are compared with recent data of the literature concerning diaryliodonium and triarylsulfonium salts. In the second part, the possibility of involving the photochemical dissociation of onium salts in a chain reaction is considered on the basis of experimental data, and the concept of electron-transfer reaction with organic free radicals is generalized.
\end{abstract}

KEY WORDS Photochemical Dissociation / Onium Salts / Cationic Polymerization / Electron-Transfer Reaction /

Recent studies of the photochemical decomposition of arylonium salts have shown the possibility to use their decomposition for an efficient initiation of the cationic polymerization of epoxides, lactones, and cyclic ethers as well as adequate vinyl monomers. Thus Schlesinger ${ }^{1}$ showed that the photolysis of aryldiazonium salts of complex halides yields Lewis acids which were used for the cationic polymerization of epoxides, e.g.,

$$
\mathrm{ArN}_{2}{ }^{+} \mathrm{MX}_{n}{ }^{-} \stackrel{h v}{\longrightarrow} \mathrm{ArX}+\mathrm{N}_{2}+\mathrm{MX}_{n-1}
$$

More recently Crivello and Lam have shown that several other onium salts, e.g., diaryliodonium, ${ }^{2}$ triarylsulfonium, ${ }^{3}$ and selenonium ${ }^{4}$ behave similarly and undergo fragmentation as shown in the following equations.

$$
\begin{aligned}
& \mathrm{Ar}_{3} \mathrm{~S}^{+} \mathrm{MX}_{n}^{-} \stackrel{h v}{\longrightarrow} \mathrm{Ar}_{2} \mathrm{~S}^{+}+\dot{\mathrm{Ar}}+\mathrm{MX}_{n}^{-} \\
& \mathrm{Ar}_{2} \mathrm{I}^{+} \mathrm{MX}_{n}{ }^{-} \stackrel{h v}{\longrightarrow} \mathrm{ArI}^{+}+\dot{\mathrm{Ar}}+\mathrm{MX}_{n}^{-}
\end{aligned}
$$

The initial formation of a diarylsulfinium or aryliodinium radical cation and an aryl radical is followed by a reaction with solvent, producing diaryl sulfide or aryl iodide, a solvent-derived radical $\dot{\mathrm{R}}$ and a proton

$$
\mathrm{Ar}_{2} \mathrm{~S}^{+}+\mathrm{RH} \longrightarrow \mathrm{Ar}_{2} \mathrm{~S}+\dot{\mathrm{R}}+\mathrm{H}^{+}
$$

$$
\mathrm{ArI}^{+}+\mathrm{RH} \longrightarrow \mathrm{ArI}+\dot{\mathrm{R}}+\mathrm{H}^{+}
$$

The Brønsted acid $\mathrm{H}^{+} \mathrm{MX}_{n}{ }^{-}$produced photochemically is responsible for further initiation of cationic polymerization, which proceeds thermally. It is the purpose of the present paper to review recent data concerning the photodissociation of onium salts, and concerning the relation of this photodissociation with the cationic polymerization and cross-linking of adequate monomers. In a second part, the possibility of induced decomposition of onium salts by chain-reaction mechanism will be discussed, and the concept of electron-transfer reaction with organic free radicals generalized. ${ }^{5}$

\section{PHOTODISSOCIATION OF ONIUM SALTS AND CATIONIC POLYMERIZATION}

\section{Diazonium Salts: Photochemical Dissociation and Cationic Initiation}

The main advantages of the use of onium salts as photoinitiators of cationic polymerization are their relatively high quantum yield of decomposition and their strong absorption region which can be shifted up to the visible region by adequate aromatic substitution. Indeed the quantum yield of decom- 
Table I. Quantum yield of photolysis of diazonium tetrafluoroborate

\begin{tabular}{lllll}
\hline \multicolumn{1}{c}{$\begin{array}{c}\text { Benzenediazonium salt } \\
\text { substituent }\end{array}$} & $\lambda_{\max }$ & $\lambda_{\text {irr }}$ & $\Phi_{\text {dec }}$ \\
\hline MDZ & $p$-Methoxy- & 318 & 316 & 0.33 \\
DEADZ & $p$-Diethylamino- & 387 & 370 & 0.62 \\
MDBDZ & 4-Morpholino-2,5-dibutyloxy- & 407 & 404 & $0.52^{\mathrm{a}}$ \\
MNDZ & 4-Morpholino-3-nitro- & 385 & 370 & 0.5 \\
\hline
\end{tabular}

a $\Phi_{\text {dec }}$ is 0.53 for the $\mathrm{SbF}_{6}{ }^{-}$salt.

position of diazonium salts with complex anions amounts to around 0.5 and depends on the ring substitution (Table I).

This decomposition can be photosensitized by xanthene dyestuffs. Indeed a complex is formed in the ground state between the dye (D) and the diazonium salt as shown by the bathochromic shift of the dye absorption band. ${ }^{6}$ On irradiation electron transfer occurs within the excited state complex, nitrogen evolves, and the Lewis acid is liberated, e.g.,

$$
\begin{gathered}
\mathrm{ArN}_{2}^{+} \mathrm{BF}_{4}^{-}+\mathrm{D}^{-} \leftrightarrows \\
{\left[\mathrm{ArN}_{2}^{+} \cdots \mathrm{D}^{-}\right] \mathrm{BF}_{4}{ }^{-} \frac{h v}{\varepsilon \text {-transfer }}} \\
{\left[\mathrm{ArN}_{2} \cdots \dot{\mathrm{D}}\right] \mathrm{BF}_{4}-\longrightarrow \mathrm{N}_{2}+[\dot{\mathrm{Ar}} \cdots \dot{\mathrm{D}}] \mathrm{BF}_{4}^{-} \longrightarrow} \\
\mathrm{ArF}^{-}+\mathrm{D}^{-}+\mathrm{BF}_{3}
\end{gathered}
$$

Some data are summarized in Table II. With erythrosine $\Phi_{\mathrm{dec}}$ amounts to unity in degassed solution, but only to 0.22 in air. The inhibiting effect of oxygen and the heavy-atom effect confirm the role of the triplet-excited state in the reaction mechanism.

Table II. Photosensitized decomposition of $\mathrm{MDBDZ}^{+} \mathrm{BF}_{4}^{-\mathrm{a}}$

\begin{tabular}{lccc}
\hline Sensitizer (Na salt) & $\lambda_{\max }$ & $\Phi_{\mathrm{dec}} / \mathrm{N}_{2}$ & $\Phi_{\mathrm{dec}} / \mathrm{Air}$ \\
\hline Fluoresceine & 510 & 0.12 & 0.04 \\
Eosine & 537 & 0.74 & 0.13 \\
Erythrosine & 537 & 1.03 & 0.22 \\
Erythrosine $^{\mathrm{b}}$ & 537 & 1.08 & 0.15 \\
\hline
\end{tabular}

a Solvent, methanol; $\lambda_{\text {irr }}, 510 \mathrm{~nm}$.

b In acetone; $\lambda_{\text {irr }}, 540 \mathrm{~nm}$.
It should be pointed out that the Lewis acid $\mathrm{BF}_{3}$ formed during the photosensitized decomposition binds itself with the anionic dye, causing a progressive decoloration of the solution. When this event occurs, the trapped boron fluoride is not available for further cationic initiation.

The photolysis of morpholinodibutyloxybenzenediazonium tetrafluoroborate (MDBDZ) has been applied to the photochemical initiation of the cationic polymerization of $\mathrm{N}$-vinylcarbazole (NVC). The reaction rate is insensitive to the presence of air oxygen, and to the addition of diphenylpicrylhydrazil. After short irradiation times, the polymerization continues in the dark following firstorder reaction kinetics, and the apparent rate constant is directly proportional to the preirradiation time, i.e., the boron trifluoride concentration formed during the photochemical fragmentation. This behavior is illustrated in Figure 1, in

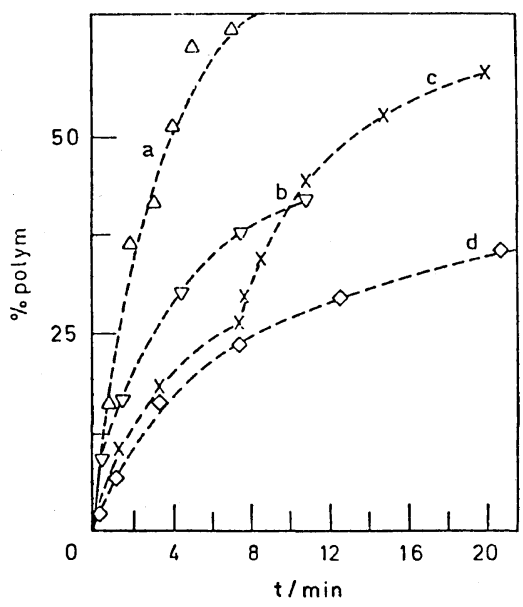

Figure 1. Dark polymerization of $N$-vinylcarbazole; [NVC], 0.26 M; solvent, dichloromethane; [MDBDZ], $5.75 \times 10^{-4} \mathrm{M}$; temp, $25^{\circ} \mathrm{C}$. Preirradiation times: (1) 60 , (b) 30 , and (c) 15 seconds. $I_{0}=2.53 \times 10^{-9} \mathrm{E} \mathrm{cm}^{-1} \mathrm{~s}^{-1}$. 
which the percent "dark" polymerization is plotted against the time.

In curve $\mathrm{c}\left(I_{0}=2.77 \times 10^{-9} \mathrm{E} \mathrm{cm}^{-2} \mathrm{~s}^{-1}\right)$ the time of preirradiation was 15 seconds as for curve d; however after slowing down of the rate, the solution was reirradiated for another 15 seconds, and the "dark" polymerization starts again according to the new amount of liberated boron trifluoride.

Worthwhile to mention is the existence of a slow thermal polymerization (dark reaction) of NVC in the presence of MDBDZ; the reaction is about 50100 times slower than the photochemically induced one. It results from the decomposition of the chargetransfer complex between the diazonium salt and NVC.

Similar photoinitiated cationic reactions have also been carried out on glycidyl methacrylate (GMA) polymers and copolymers with methyl methacrylate in the presence of the same MDBDZ photoinitiator. For solubility requirements of the diazonium salt the polymers always contained 5\% methacrylonitrile.

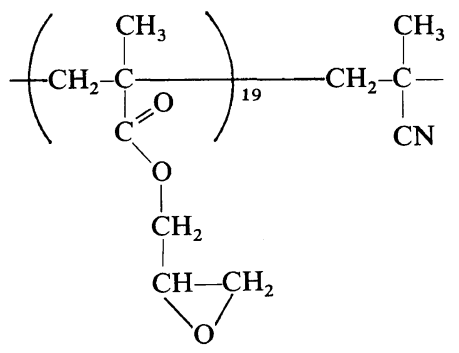

COP $95 T_{\mathrm{g}} \sim 60^{\circ} \mathrm{C}$

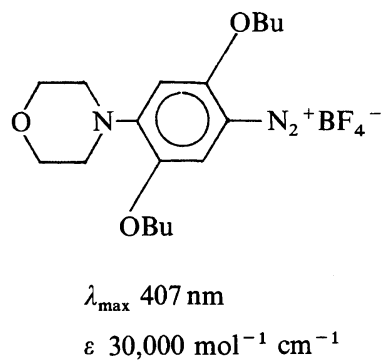

In these cases, cross-linking occurs as consequence of epoxy-ring opening polymerization under the influence of the boron trifluoride produced during a short preirradiation period. The reaction was followed gravimetrically.

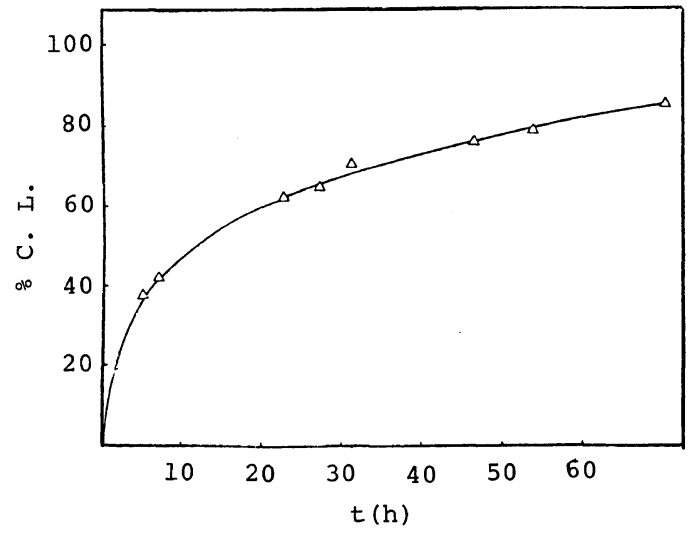

Figure 2. Cross-linking of poly(glycidyl methacrylate); temp, $25^{\circ} \mathrm{C}$. Preirradiation: $30 \mathrm{~s} ; \lambda_{\text {irr }}, 404 \mathrm{~nm}$.

As can be seen from Figure 2, this cross-linking reaction is however very slow at room temperature, and presents a prolonged post-effect of 50 60 hours. The reason for this slowness is double: the reaction temperature is much below the $T_{\mathrm{g}}$ of the polymer $\left(60^{\circ} \mathrm{C}\right)$; on the other hand the photochemically produced Lewis acid $\mathrm{BF}_{3}$ is trapped by the basic morpholine group. A thermal development is thus required in order to improve the diffusion phenomena and in order to make free the boron trifluoride necessary for the epoxide-ring opening. Therefore after irradiation heating at $70^{\circ} \mathrm{C}$ during 5 minutes has always been applied. The rate of crosslinking of PGMA increases with the concentration of diazonium salt, then passes through a maximum at $0.2 \%$ weight. The reason for a less efficient crosslinking at higher DZ-concentration results from a front effect by which $\mathrm{BF}_{3}$ is not uniformly distributed in the film.

Using several copolymers of GMA with MMA in which the GMA content varied from 10 to $95 \%$, the rate of cross-linking was examined in function of the time of irradiation.

As obvious from Figure 3, copolymer 70 crosslinks as efficiently as the copolymer 95 , while COP 50 is noticeably slower. A relatively high epoxidegroup concentration is thus required for efficient cross-linking. Finally the rate of cross-linking depends also on the nature of the diazonium cation and of its complex anion. Though the quantum yield of decomposition of the diazonium salts is independent from the nature of the anion, nevertheless for both DEADZ and MDBDZ salts, the cross- 


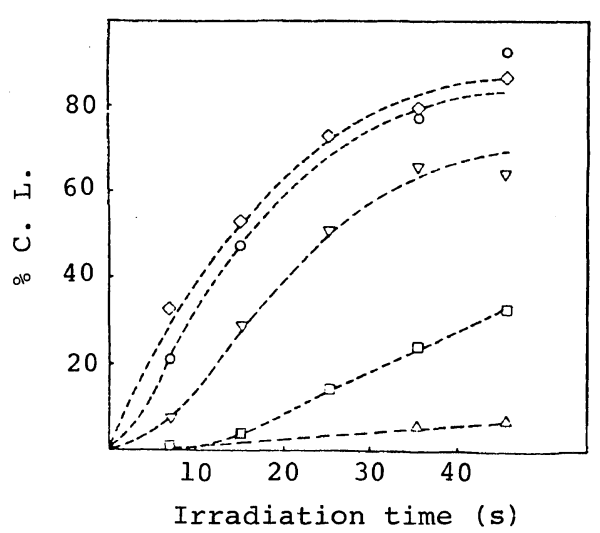

Figure 3. Cross-linking of (Gly-MMA) copolymer. Influence of the irradiation time: $\diamond$, COP 95; $\mathrm{O}, \mathrm{COP}$ $70 ; \nabla, \operatorname{COP} 50 ; \square, \operatorname{COP} 20 ; \triangle, \operatorname{COP} 10 ; \lambda_{\text {irr }}, 404 \mathrm{~nm}$; development, $10 \mathrm{~min} / 80^{\circ} \mathrm{C} ; I_{0}=5.5 \times 10^{-9} \mathrm{E} \mathrm{cm}^{-2} \mathrm{~s}^{-1}$.

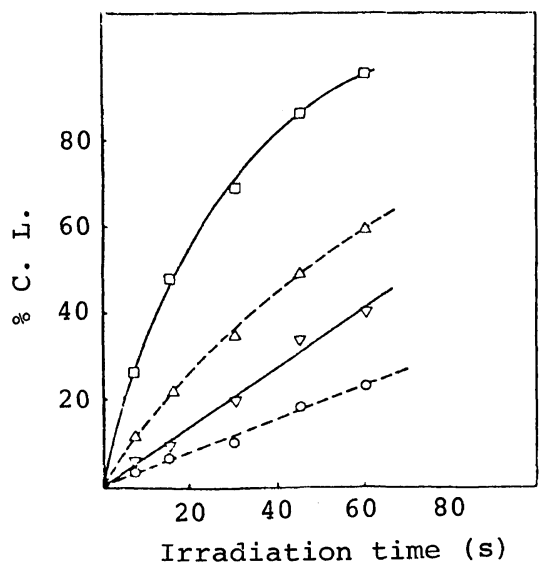

Figure 4. Cross-linking of poly(glycidyl methacrylate). Influence of the diazonium salt: $\mathrm{O}, \mathrm{DEADZ}^{+} \mathrm{SbF}_{6}{ }^{-}$; $\nabla, \mathrm{MDBDZ}^{+} \mathrm{SbF}_{6}{ }^{-} ; \triangle, \mathrm{DEADZ}^{+} \mathrm{BF}_{4}{ }^{-} ; \square$ $\mathrm{MDBDZ}^{+} \mathrm{BF}_{4}^{-}$; development, $5 \mathrm{~min} / 70^{\circ} \mathrm{C}$.

linking efficiency, i.e., ring-opening polymerization of the epoxides, is higher with the tetrafluoroborate than with the corresponding hexafluoroantimonate. This reactivity order differs from that observed for the photoinitiated polymerization of cyclohexane oxide and styrene oxide in the presence of $\operatorname{di}(p$ alkylphenyl) iodonium salts for which the efficiency of the Brønsted acids follows the order $\mathrm{HSbF}_{6} \gg \mathrm{HAsF}_{6}>\mathrm{HPF}_{6} \gg \mathrm{HBF}_{4}$, i.e., depends on the size of the corresponding anions. ${ }^{3}$

It should, however, be pointed out that our data with PGMA refer to cross-linking reactions in solid films where diffusion phenomena must exerce a predominant influence, while the experiments of Crivello and Lam refer to solutions polymerization (neat monomer).

\section{Sulfonium and Iodonium Salts}

From the point of view of thermal stability, the use of diazonium salts may be questionable, especially if electron-withdrawing substituents are present in the aromatic rings, although this stability can be improved by addition of some acid, e.g., oxalic acid. With electron-donor groups (morpholino and diethylamino) in the ring the thermal stability is satisfactory. Iodonium and sulfonium salts are stable compounds, and can in many cases be preferred to the diazonium salts; these onium salts were very carefully studied by Crivello and Lam. ${ }^{2-4}$ They have a mean decomposition quantum yield $\Phi_{\mathrm{dec}}=0.2$, which is lower than that of the diazonium salts. Moreover they absorb mainly much below $300 \mathrm{~nm}$, and their absorption can only moderately be extended to longer wavelengths by substitution. Their decomposition can, however, be photosensitized, e.g., by cationic acridine dyes for diaryliodonium salts. ${ }^{3}$ Pappas assumes exciplex formation between the excited dye $\left(D^{*}\right)$ and the aryl onium salt (e.g., diphenyliodonium hexafluoroarsenate); this exciplex decomposes mainly by electron transfer ${ }^{7}$ and possibly by aryl iodine bond cleavage following the scheme.

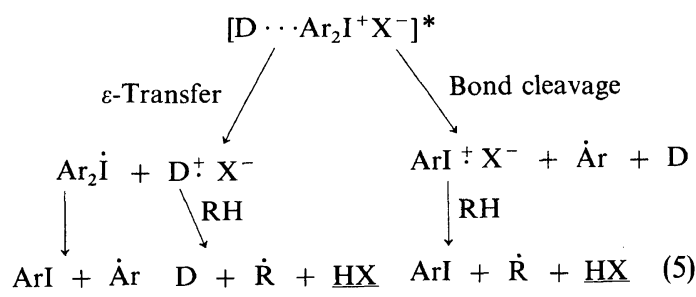

The photosensibilization of triarylsulfonium salts by perylene can similarly be represented; it is also insensitive to air oxygen. It must be stressed that with these compounds the photosensitized decomposition of the onium salts initiates cationic polymerization contrarily to the diazonium salts decomposition when this is sensitized by xanthene dyes. The Brønsted acids have been used for the cationic polymerization of cyclic ethers (THF, oxetane), lactones, cyclic acetals, vinyl ethers, $\alpha$ - 
methylstyrene, several oxiranes, dioxiranes, and unsaturated derivatives. ${ }^{2}$ Worthwhile to mention is that the generation of both free radical and Brønsted acid was demonstrated by the simultaneous formation of two homopolymers from a mixture of cyclohexene oxide and methyl methacrylate by photolysis of tris(4-methoxyphenyl)sulfonium hexafluoroarsenate in their presence. $^{3}$

The photodissociation of dialkylphenacylsulfonium salts can also be used for cationic polymerization; this dissociation is, however, thermally reversible by reaction of the acyl dialkyl sulfurane ylid with the Brønsted acid. The method looks attractive because it should afford the possibility, at least in principle, to synthesize a polymer with a functionalized acyl sulfonium endgroup.

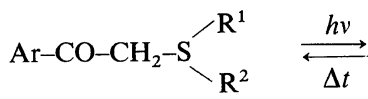

$$
\begin{aligned}
& \mathrm{X}^{ \pm} \mathrm{Ar}-\mathrm{CO}-\mathrm{CH}=\mathrm{S}_{\backslash \mathrm{R}^{2}} / \underline{\mathrm{HX}} \\
& \mathrm{HX}+\mathrm{M} \longrightarrow \mathrm{HM}^{+} \mathrm{X}^{-} \underset{\mathrm{M}}{\longrightarrow} \mathrm{HM}_{n}^{+} \mathrm{X}^{-}
\end{aligned}
$$

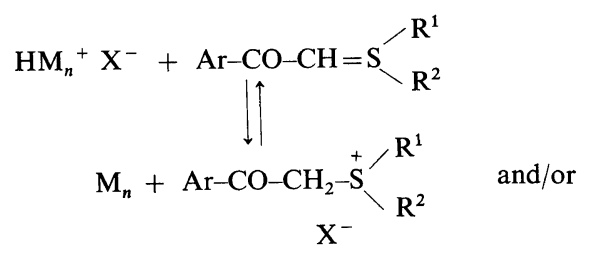

$$
\begin{aligned}
& \underset{\mathrm{S}^{+}}{\mathrm{Ar}-\mathrm{CO}-\mathrm{CH}} \underset{\mathrm{R}^{2}}{-\mathrm{R}^{1}} \mathrm{X}^{-}
\end{aligned}
$$

Mention should also be made of the use of thiopyrylium tetrafluoroborate and hexafluorophosphate as photoinitiator for photocuring of epoxides. ${ }^{8}$ These compounds have the advantage to absorb in the visible spectrum. Their dark stability is however insufficient, especially when electrons withdrawing groups are present in the aromatic ring.

\section{PHOTODISSOCIATION OF ONIUM SALTS INDUCED BY CHAIN REACTION}

The possibility to decompose photochemically onium salts in a chain reaction leading to the generation of several cationic initiators is an important problem, because it implicates a supplementary amplification of the quantum yield independently of the degree of polymerization of each growing polymer chain..$^{9-11}$ Indeed it is known that onium salts oxidize easily hydroxyalkyl radicals by electron-transfer reaction, resulting in fragmentation with formation of an aryl radical and resonance-stabilized carbocation. ${ }^{10}$

$$
\begin{aligned}
& \mathrm{RC} H \mathrm{HOH}+\mathrm{Ar}_{2} \mathrm{I} \stackrel{\mathrm{MXN}_{2}{ }^{-}}{\longrightarrow} \begin{array}{l}
\mathrm{N}_{2} \\
\mathrm{ArI}
\end{array}+\dot{\mathrm{Ar}}+ \\
& \mathrm{Ar}_{3} \mathrm{~S}^{+} \quad \mathrm{Ar}_{2} \mathrm{~S} \\
& \text { R- } \stackrel{+}{\mathrm{C}} \mathrm{HOH}(\hookrightarrow \mathrm{RCH}=\stackrel{+}{\mathrm{O}} \mathrm{H})+\mathrm{MX}_{n}^{-}
\end{aligned}
$$

Addition of these radicals to alkyl vinyl ether or abstraction of an hydrogen atom from an oxidizable substrate $\mathrm{RCH}_{2} \mathrm{OH}$ (e.g., methanol) or cyclic ether (THF) makes a chain process feasible, yielding several Brønsted acids molecules for one primary radical.

$$
\dot{\mathrm{Ar}}+\mathrm{CH}_{2}=\mathrm{CHOR} \longrightarrow \mathrm{ArCH}_{2}-\dot{\mathrm{C}} \mathrm{H}-\mathrm{OR}
$$

$$
\dot{\mathrm{A}} \mathrm{r}+\mathrm{RCH}_{2} \mathrm{OH} \longrightarrow \mathrm{ArH}+\mathrm{R} \dot{\mathrm{C}} \mathrm{HOH}
$$

In the case of the diazonium salts, such a chain decomposition was clearly observed in methanol solution; in agreement with the data of Becker ${ }^{12}$ electron transfer takes place if the diazonium salt has an appropriate reduction potential. It is enhanced by an increased electron affinity, e.g., by the presence of a strong electron attracting group in the aromatic ring. The chain reaction can be represented as follows in methanol and in dioxane.

$$
\left.\begin{array}{ll} 
& \mathrm{ArN}_{2}{ }^{+} \stackrel{h v}{\mathrm{e}^{-}} \mathrm{ArN}_{2} \longrightarrow \dot{\mathrm{Ar}}+\mathrm{N}_{2} \\
\text { In methanol } & \dot{\mathrm{Ar}}+\mathrm{CH}_{3} \mathrm{OH} \longrightarrow \mathrm{ArH}+\dot{\mathrm{C}}_{2} \mathrm{OH} \\
& \mathrm{ArN}_{2}{ }^{+}+\dot{\mathrm{C}} \mathrm{H}_{2} \mathrm{OH} \longrightarrow \dot{\mathrm{Ar}}+\mathrm{N}_{2}+\mathrm{CH}_{2} \mathrm{O}+\mathrm{H}^{+}
\end{array}\right\} \text {Chain propagation }
$$




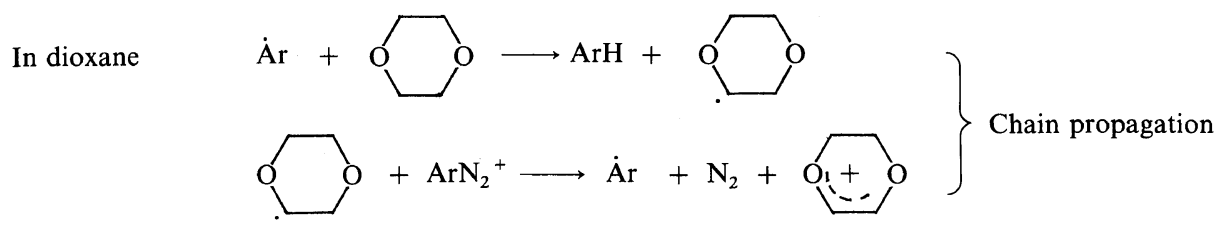

Table III. Photolysis of arenediazonium salts in methanol $\left(10^{-2} \mathrm{M}\right.$ oxalic acid)

\begin{tabular}{|c|c|c|c|c|}
\hline \multirow{2}{*}{$\begin{array}{l}\text { Diazonium salts } \\
\text { DZ }^{\mathrm{a}}\end{array}$} & \multirow{2}{*}{ Sensitizer } & \multirow{2}{*}{$\frac{\lambda_{\mathrm{irr}}}{\mathrm{nm}}$} & \multicolumn{2}{|c|}{ Quantum yield of decomposition } \\
\hline & & & In air & Under nitrogen \\
\hline 1 & - & 313 & 0.40 & 6.3 \\
\hline 2 & - & 371 & 0.50 & $4.1-4.3-4.6$ \\
\hline 3 & - & 371 & 0.50 & $13.5-17$ \\
\hline 2 & $\mathrm{ERNa}^{\mathrm{b}}$ & 551 & 0.12 & 19 \\
\hline 3 & $\mathrm{ERNa}$ & 551 & 0.13 & 27 \\
\hline 2 & $\mathrm{MNK}^{\mathrm{c}}$ & 313 & $(0.09)^{\mathrm{d}} 0.12$ & $(13)^{d} 23-27$ \\
\hline 3 & MNK & 313 & 0.19 & 25 \\
\hline
\end{tabular}

a DZ-1, 4-chlorobenzenediazonium tetrafluoroborate; DZ-2, 4-morpholino-3-nitro-benzenediazonium tetrafluoroborate; DZ-3, 4-morpholino-3-nitro-benzenediazonium trioxalatoferrate. $\mathrm{Fe}^{\mathrm{IIII}}\left(\mathrm{C}_{2} \mathrm{O}_{4}\right)_{3}[\mathrm{DZ}]=(5.1-5.6) \times 10^{-5} \mathrm{M}$.

b ERNa, erythrosine disodium salt, $[\mathrm{ERNa}]=2 \times 10^{-5} \mathrm{M}$.

c MNK, methyl 2-naphthyl ketone, $[\mathrm{MNK}]=(9.6-10.3) \times 10^{-4} \mathrm{M}$.

d In dioxane, instead of methanol.

It is assumed that the electron necessary in the initiation step originates from the complex anion of the DZ salt or from the reaction medium. Such chain decomposition does not necessitate the use of methanol; dioxane and tetrahydrofuran are also very adequate as solvents.

Some new experimental results are summarized in Table III. In these experiments oxalic acid was always added for the stabilization of the diazonium salts.

As can be seen in this table, chain decomposition requires the absence of air oxygen on account of its inhibiting effect on radical processes. In presence of oxygen only a quantum yield around 0.5 can be observed. Noteworthy is the enhanced efficiency of decomposition of DZ3 compared to DZ2, $\Phi_{\text {dec }}$ being 17 instead of $4-5$; it is related with the much higher oxidability of the trioxalatoferrate anion compared to that of the tetrafluoroborate.

The behavior of both diazonium salts 2 and 3 in the absence of sensitizer is illustrated in Figure 5, where the logarithm of the optical density is plotted against the total absorbed-light intensity. While in air both DZ salts behave similarly and decompose only slowly, under nitrogen the photolysis proceeds much more rapidly, especially in the case of the

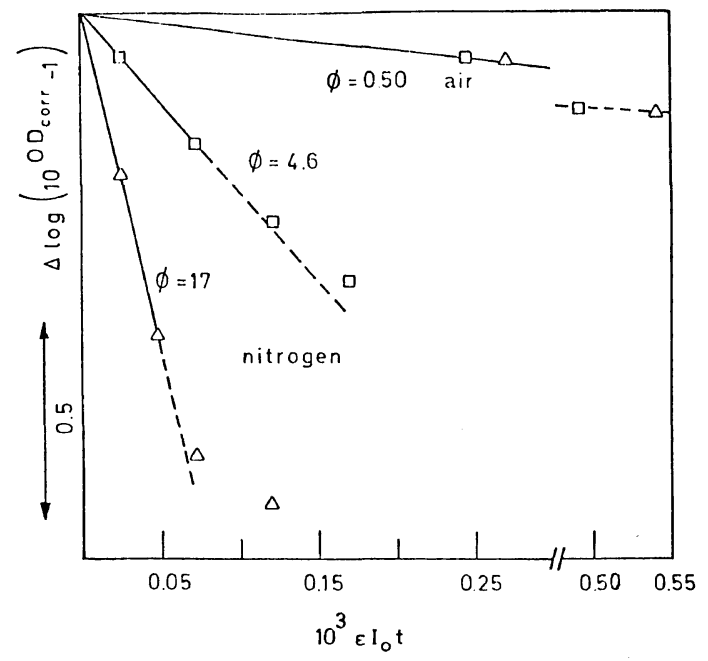

Figure 5. Photolysis of diazonium salts in the presence of air and under nitrogen: $\left[\mathrm{DZ}^{+} \mathrm{X}^{-}\right]=(5.1-5.6) \times 10^{-5}$; $\square$, MNDZ tetrafluoroborate; solvent, methanol; (oxalic acid) $10^{-2} ; \triangle$, MNDZ trioxalatoferrate; $I_{0}=5 \times 10^{-10} \mathrm{E}$ $\mathrm{cm}^{-2} \mathrm{~s}^{-1} ; \lambda_{\text {irr }}=371 \mathrm{~nm}$. 
trioxalatoferrate anion.

This chain decomposition can also proceed very efficiently in the presence of a photosensitizer. With sodium erythrosine $\Phi$-values above 20 can easily be obtained. More interesting is, however, the sensiti- zation with methyl 2-naphthyl ketone; in this case the triplet-excited state MNK abstracts hydrogen from methanol, producing ketyl and hydroxymethyl radicals. Starting from these radicals efficient electron transfer to the $\mathrm{DZ}$-salts becomes operative.

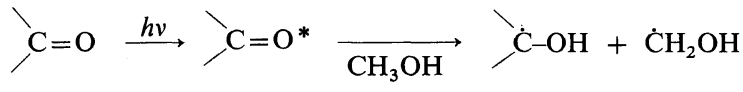

$$
\begin{aligned}
& \dot{\mathrm{C}} \mathrm{H}_{2} \mathrm{OH}+\mathrm{ArN}_{2}{ }^{+} \longrightarrow \mathrm{CH}_{2} \mathrm{O}+\mathrm{H}^{+}+\mathrm{N}_{2}+\dot{\mathrm{Ar}} \longrightarrow \\
& \stackrel{\mathrm{C}}{-} \mathrm{OH}+\mathrm{ArN}_{2}{ }^{+} \longrightarrow, \mathrm{C}=\mathrm{O}+\mathrm{H}^{+}+\mathrm{N}_{2}+\dot{\mathrm{Ar}} / \text { Chain reaction }
\end{aligned}
$$

Comparison experiments on polymeric films have been carried out mainly in poly(vinyl alcohol) because of its chemical analogy with methanol, and on account of the low solubility and low permeability of oxygen in this polymer. Some experimental results are summarized in Table IV.

Table IV. Photolysis of 4-morpholino-3nitro- $\mathrm{DZ}^{+} \mathrm{BF}_{4}^{-}$in $\mathrm{PVOH}-$ film

\begin{tabular}{cccl}
\hline Plasticizer & Sensitizer & $\lambda_{\text {irr }}$ & $\Phi_{\text {dec }}$ \\
\hline- & - & 371 & 0.16 \\
$40 \%$ PEG $^{\mathrm{a}}$ & - & 371 & 0.17 \\
$4 \%$ PEG & Sodium erythrosine & 540 & 0.33 \\
- & $\mathrm{K}_{3} \mathrm{Fe}\left(\mathrm{C}_{2} \mathrm{O}_{4}\right)_{3} \cdot 3 \mathrm{aq}^{\mathrm{b}}$ & 313 & 0.23 \\
$28 \%$ PEG & $\mathrm{K}_{3} \mathrm{Fe}\left(\mathrm{C}_{2} \mathrm{O}_{4}\right)_{3} \cdot 3 \mathrm{aq}^{\mathrm{b}}$ & 313 & 3 \\
$35 \%$ PEG & $\mathrm{K}_{3} \mathrm{Fe}\left(\mathrm{C}_{2} \mathrm{O}_{4}\right)_{3} \cdot 3 \mathrm{aq}^{\mathrm{b}}$ & 313 & 3.9 \\
\hline
\end{tabular}

a PEG, poly(ethylene glycol), molecular weight (MW), 400.

b Film composition, $\mathrm{PVOH}-\mathrm{K}_{3} \mathrm{Fe}\left(\mathrm{C}_{2} \mathrm{O}_{4}\right)_{3} \cdot 3 \mathrm{H}_{2} \mathrm{O}-\mathrm{DZ}^{+}$ salt, $150: 15: 1$ weight ratio.

In the absence of plasticizer the quantum yield of decomposition is always low; as expected chain decomposition necessitates diffusion of the reagents. In the presence of low-molecular-weight poly(ethylene glycol), sensitization with potassium ferrioxalate permits to obtain $\Phi$-values of 3 to 4 following the reaction mechanism:

$$
\begin{aligned}
& \mathrm{Fe}\left(\mathrm{C}_{2} \mathrm{O}_{4}\right)_{3}{ }^{3-} \stackrel{h v}{\longrightarrow} \mathrm{Fe}^{2+}+2 \mathrm{C}_{2} \mathrm{O}_{4}{ }^{2-}+\mathrm{C}_{2} \mathrm{O}_{4}{ }^{-} \\
& \mathrm{C}_{2} \mathrm{O}_{4}{ }^{-}+\mathrm{Fe}\left(\mathrm{C}_{2} \mathrm{O}_{4}\right)_{3}{ }^{3-} \longrightarrow \\
& \mathrm{Fe}^{2+}+2 \mathrm{CO}_{2}+3 \mathrm{C}_{2} \mathrm{O}_{4}{ }^{2-}
\end{aligned}
$$

$$
\begin{aligned}
& \mathrm{Fe}^{2+}+\mathrm{ArN}_{2}{ }^{+} \longrightarrow \\
& \mathrm{Fe}^{3+}+\mathrm{N}_{2}+\stackrel{\dot{A} \mathrm{r}}{\downarrow} \mathrm{ArN}_{2}{ }^{+} \\
& \text {Chain decomposition }
\end{aligned}
$$

Likely poly(ethylene glycol) itself participates to the chain process. These results confirm the data of Schiller et al. ${ }^{13}$ on $p$-chlorobenzenediazonium tetrafluoroborate in poly(vinyl alcohol) and poly(vinyl formal); above the glass temperature a chain reaction was obtained with a quantum yield above 50 in highly softened layers.

In the chain processes described above the formation of a first electrodonating free radical is required for the initiation step (eq 7-9).

As pointed out by Lewdith, ${ }^{9}$ it should be without any importance whether this initial free radical is obtained thermally or by photochemical fragmentation. It is only the combination of suitable free radical sources with oxidizing cations which is the prerequisite to promote the cationic polymerization of alkyl vinyl ether and cyclic ether. Thus instead of resulting from the photolysis of onium salts, as described above, the formation of electron-donor free radical can advantageously be formed by photolysis of benzoine alkyl ethers, $\mathrm{C}_{6} \mathrm{H}_{5} \mathrm{CH}(\mathrm{OR})$ $\mathrm{CO}-\mathrm{C}_{6} \mathrm{H}_{5}$ or dialkoxyphenylacetophenone.

In the presence of a vinyl monomer (polymerizable cationically) free-radical polymerization occurs. The growing chain will donate an electron to the diaryliodonium or diazonium salt (eq) and continue to grow cationically while the new free radical initiates a new polymeric chain (eq 7). Thus Ledwith $^{9,11}$ described recently the free-radical in- 
duced decomposition of ditolyliodonium hexafluorophosphate and the resulting photoinitiated polymerization of tetrahydrofuran, by irradiating dimethoxyphenylacetophenone in the presence of THF. Around 30 cationic chains were formed for each photon absorbed. With cyclic ethers first hydrogen abstraction occurs, followed by electron transfer with the onium salt.

$$
\begin{aligned}
& \dot{\mathrm{R}}+\zeta_{\mathrm{O}} \longrightarrow \mathrm{RH}+\square_{\mathrm{O}} . \\
& \bigcup_{\mathrm{O}}+\mathrm{Ar}_{2} \mathrm{I}^{+} \mathrm{PF}_{6}{ }^{-} \longrightarrow \\
& \dot{A} r+\operatorname{ArI}+\left[\begin{array}{c}
+, i \\
\hdashline-i
\end{array}\right] \quad P F_{6}^{-} \\
& \dot{\mathrm{A}} \mathrm{r}+\square_{\mathrm{O}} \longrightarrow \mathrm{ArH}+\square_{\mathrm{O}}
\end{aligned}
$$

In such processes, $\dot{R}$ must not necessarily be a free radical; it may be a triplet-excited state ketone, e.g., the cationic polymerization of THF by irradiation of diazonium salt in the presence of benzophenone. Inversely, the electron acceptor needs not to be an onium salt. The cationic polymerization of butyl vinyl ether, tetrahydrofuran or a cyclohexyl bisepoxide in the presence of phenylazotriphenylmethane and of a silver salt with non-nucleophilic anion, as silver hexafluorophosphate, illustrates clearly this new aspect of the interrelations of free radical and cationic polymerization, based on electron-transfer reactions with organic radical

$$
\begin{aligned}
& \mathrm{Ph}-\mathrm{N}=\mathrm{N}-\mathrm{CPh}_{3} \stackrel{h v}{\longrightarrow} \dot{\mathrm{Ph}}+\mathrm{N}_{2}+\mathrm{Ph}_{3} \dot{\mathrm{C}} \\
& \mathrm{Ph}_{3} \dot{\mathrm{C}}+\mathrm{Ag}^{+} \mathrm{PF}_{6}^{-} \longrightarrow \mathrm{Ph}_{3} \mathrm{C}^{+} \mathrm{PF}_{6}^{-}+\mathrm{Ag} \\
& \underset{\mathrm{OC}_{4} \mathrm{H}_{9}}{\sim \mathrm{CH}_{2}-\dot{\mathrm{C}} \mathrm{H}}+\underset{\mathrm{AgPF}}{\longrightarrow} \longrightarrow \underset{\mathrm{CH}_{2}-\stackrel{+}{\mathrm{C}} \underset{\mathrm{H}}{\mathrm{H}}-\mathrm{OC}_{4} \mathrm{H}_{9}+\mathrm{Ag}}{\mathrm{PF}_{6}^{-}}
\end{aligned}
$$

In the practice, however, a drawback of the freeradical promoted cationic polymerization resides in its sensibility to atmospheric oxygen, which inhibits almost completely the chain reaction. It is still, at least provisionally, a serious limitation for further technical applications.
As general conclusion, it may be stated that the photochemical initiation of the cationic polymerization has taken in evidence the importance for polymer and organic chemistry of electron-transfer reactions in our further understanding of organic reaction mechanisms.

Acknowledgement. The authors are indebted to the Ministry of Scientific Programmation and to the Centre of High Polymer Research-IWONL, Belgium for financial support and for research fellowships of two of them (A.A., J.V.E.).

\section{REFERENCES}

1. S. I. Schlesinger, Photogr. Sci. Eng., 18, 387 (1974); Polym. Eng. Sci., 14, 513 (1974); U. S. Patent 3708296 (1973).

2. J. V. Crivello, "U.V. Curing, Science and Technology," S. P. Pappas, Ed., Marketing Corp., Stamford, Conn., 1978, p 23); J. V. Crivello and J. H. W. Lam, Macromolecules, 10, 1307 (1977); J. Polym. Sci., Polym. Symp., No. 56, 383 (1976); J. Polym. Sci., Polym. Chem. Ed., 16, 2441 (1978); J. V. Crivello, J. H. W. Lam, and C. N. Volante, J. Radiat. Curing, 4, 2 (1977).

3. J. V. Crivello and J. H. W. Lam, J. Polym. Sci., Polym. Chem. Ed., 16, 2441 (1978); ibid., 17, 977, 1059 (1979); Polym. Prepr., Am. Chem. Soc., Div. Polym. Chem., 20, 415 (1979); J. V. Crivello, J. H. W. Lam, J. E. Moore, and S. H. Schroeter, J. Radiat. Curing, 5, 2 (1978); J. Polym. Sci., Polym. Chem. Ed., 17, 3845 (1979); J. Polym. Sci., Polym. Lett. Ed., 17, 759 (1979).

4. J. V. Crivello and J. H. W. Lam, J. Polym. Sci., Polym. Chem. Ed., 17, 1047 (1979).

5. H. G. Viehe, R. Merenyi, L. Steller, and Z. Janousek, Angew. Chem., 91, 982-997 (1979).

6. P. E. Macrae and T. R. Wright, J. Chem. Soc., Chem. Commun., 898 (1974).

7. S. P. Pappas and J. H. Jilek, Photogr. Sci. Eng., 23, 140 (1979).

8. A. D. Ketley and J. H. Tsao, J. Radiat. Curing, 6 (No. 4), 22 (1979).

9. A. Ledwith, Makromol. Chem. Suppl., 3, 348 (1979); Pure Appl. Chem., 51, 159 (1979).

10. J. E. Packer and R. K. Richardson, J. Chem. Soc., Perkin Trans. 2, 751 (1975); J. W. Knapczyk, J. J. Lubinowski, and W. E. McEwen, Tetrahedron Lett., 3739 (1972); J. W. Knapczyk and W. E. McEwen, J. Org. Chem., 35, 2539 (1970).

11. A. Ledwith, Polymer, 19, 1217 (1978); F. A. M. Abdul-Rasoul, A. Ledwith, and Y. Yagei, Polymer, 19, 1219 (1978); F. A. M. Abdul-Rasoul, A. Ledwith, and Y. Yagei, Polym. Bull., 1, 1 (1978). 
12. H. G. O. Becker, E. Fanghänel, and K. Schiller, Wiss. Z. Tech. Hochsch. Leuna-Merseburg, 16, 322 (1974); H. G. O. Becker, J. Signal A. M., 3, 381 (1975); H. G. O. Becker and G. Israël, Z. Phys. Chem. (Leipzig), 256, 436 (1975); H. G. O. Becker, R. Elish, G. Israël, G. Kroha, W. Kroha, O. Brede, and R. Mehnert, Z.
Prakt. Chem., 319, 98 (1977); H. G. O. Becker, G. Hoffmann, and G. Israël, ibid., 319, 1021 (1977); H. G. O. Becker, G. Schukat, and M. G. Kuzmin, ibid., 317, 229 (1975).

13. K. Schiller, E. Fanghänel, R. Ackerman, and G. Libor, J. Signal A. M., 7, 135 (1979). 